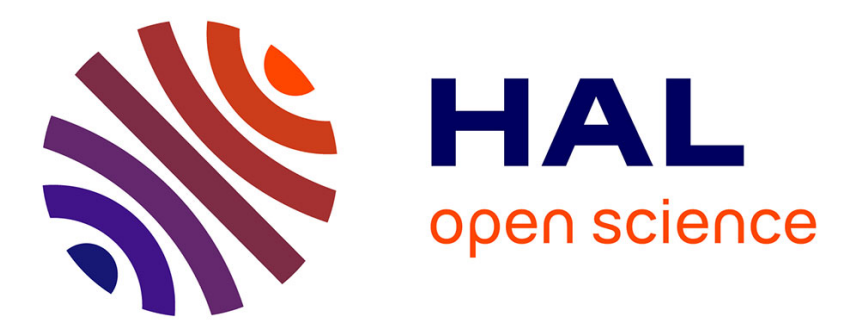

\title{
Supporting Knowledge-Centered Business Collaboration for Wind Power Plants
}

Christian Zinke, Johannes Schmidt, Andreas Nareike

\section{To cite this version:}

Christian Zinke, Johannes Schmidt, Andreas Nareike. Supporting Knowledge-Centered Business Collaboration for Wind Power Plants. 16th Working Conference on Virtual Enterprises (PROVE), Oct 2015, Albi, France. pp.255-262, 10.1007/978-3-319-24141-8_23 . hal-01437894

\section{HAL Id: hal-01437894 \\ https://hal.inria.fr/hal-01437894}

Submitted on 17 Jan 2017

HAL is a multi-disciplinary open access archive for the deposit and dissemination of scientific research documents, whether they are published or not. The documents may come from teaching and research institutions in France or abroad, or from public or private research centers.
L'archive ouverte pluridisciplinaire HAL, est destinée au dépôt et à la diffusion de documents scientifiques de niveau recherche, publiés ou non, émanant des établissements d'enseignement et de recherche français ou étrangers, des laboratoires publics ou privés.

\section{(c)(1)}

Distributed under a Creative Commons Attribution| 4.0 International License 


\title{
Supporting Knowledge-centered Business Collaboration for Wind Power Plants
}

\author{
Christian Zinke ${ }^{1}$, Johannes Schmidt ${ }^{1,2}$, Andreas Nareike ${ }^{1}$ \\ ${ }^{1}$ University of Leipzig, Augustsplatz 10, \\ 04109 Leipzig, Germany \\ \{zinke, jschmidt, nareike\}@informatik.uni-leipzig.de \\ ${ }^{2}$ Institute for Applied Informatics (InfAI) e.V., Hainstraße 11 \\ 04109 Leipzig, Germany
}

\begin{abstract}
In Germany, the importance of renewable energy resources increased significantly within the last years. In contrast to conventional power plants, there are highly interactive and complex value-added networks around such an energy resource. Today, the members of these networks mainly have to cope with information gaps or other issues regarding documentation quality. These challenges become critical in the context of knowledge intensive business-tobusiness processes. To encourage better business collaboration, a holistic knowledge-centered approach is needed. The digital Plant Lifecycle Record (PLR) addresses the given challenges in the context of wind turbines. Based on this approach, the members of the value-added networks cooperatively manage a plant-related knowledge base. By means of a use case, the general concepts of the Plant Lifecycle Record are introduced. Furthermore, empirically collected expectations of the most important stakeholders are discussed.
\end{abstract}

Keywords: renewable energy, business collaboration, documentation, knowledge management, Plant Lifecycle Record

\section{Introduction}

In Germany, the number of wind power plants (WPP) increased significantly within the last decade [1]. In contrast to conventional power plants, WPPs are widely distributed. Remote monitoring and remote services of WPPs enable an unattended operation. Thus, no permanent on-site staff is required. If needed, the plant owner can commission local service providers, which are often specialized on knowledge intensive business tasks. For example, maintenance services depend on up-to-date and complete information about the structure of the WPP and a complete maintenance history. Another example are surveyor services, which require a complete and comprehensive list of certificates and the latest technical documentation. All these service providers interact within a dynamic market whereas WPPs are incorporated in a highly flexible value-added network. 
Today, most challenges in business collaboration and service commission result from missing information as well as from the lack of standardized business processes, services, and information technology. The digital Plant Lifecycle Record (PLR) addresses these challenges by providing a shared knowledge base that satisfies the specific information needs of every stakeholder. Based on this approach, the members of the valued-added network can cooperatively share and manage plant-related knowledge. This results in lower process costs and improved collaboration within the network.

This paper addresses the following research questions. 1) Which requirements, potentials, and stakeholder types are important for a knowledge-based approach in the wind energy domain? 2) What are the most relevant structural elements of the PLR? Therefore, this paper has the following structure. Firstly, the used methodology is introduced. Secondly, the theoretical framework of the Business Collaboration Pyramid by Ewig [2] is discussed, including a short discourse about the dependencies between organizational structure, knowledge and information technology. Thirdly, in section 4, empirical based requirements and innovation potentials are presented and the overall structure of the digital PLR is introduced. Finally, a use case and an outlook on further research will be given.

\section{Methods and Methodological Remarks}

The methodology of this work is oriented towards the design science ${ }^{1}$ with the aim "to create things that serve human purposes" [3]. The resulting artefacts need to be designed and evaluated [4]. Therefore, methods and knowledge of natural and social sciences are applied.

Following a middle-out strategy, the presented findings result from two sources. The first source is the relevant literature, which provides a theoretical description of the problem and the context (top-down). The second source is an explorative semistructured expert survey (bottom-up) which aims to identify different stakeholder viewpoints (called ideal-types) and their particular requirements on the PLR. The extracted ideal-types help to understand the specific information needs of the stakeholders as well as the practical potential of the PLR approach.

\section{Related Work}

Collaboration in value-added networks is a young phenomenon with growing interest. Due to organizational specialization and outsourcing activities in the industry, collaboration issues emerged. This work mainly refers to the business collaboration framework developed by Ewig [2] that is introduced below. Additionally, other related works in the field of organizational theory and knowledge management are presented.

\footnotetext{
${ }^{1}$ In contrast to natural sciences and social sciences, which try to understand the reality.
} 


\subsection{Business Collaboration Pyramid}

Ewig [2] introduced a framework to describe the transformation process of business and value-chains towards business collaboration. The current state of this transformation can be described with the help of the Collaborative Business Pyramid. This pyramid consists of five dimensions (strategy, organizational operations, organizational structure, information structure, and information technology) with three maturity levels each. In this work, only three dimensions and their mutual relations are investigated (see Fig. 1).

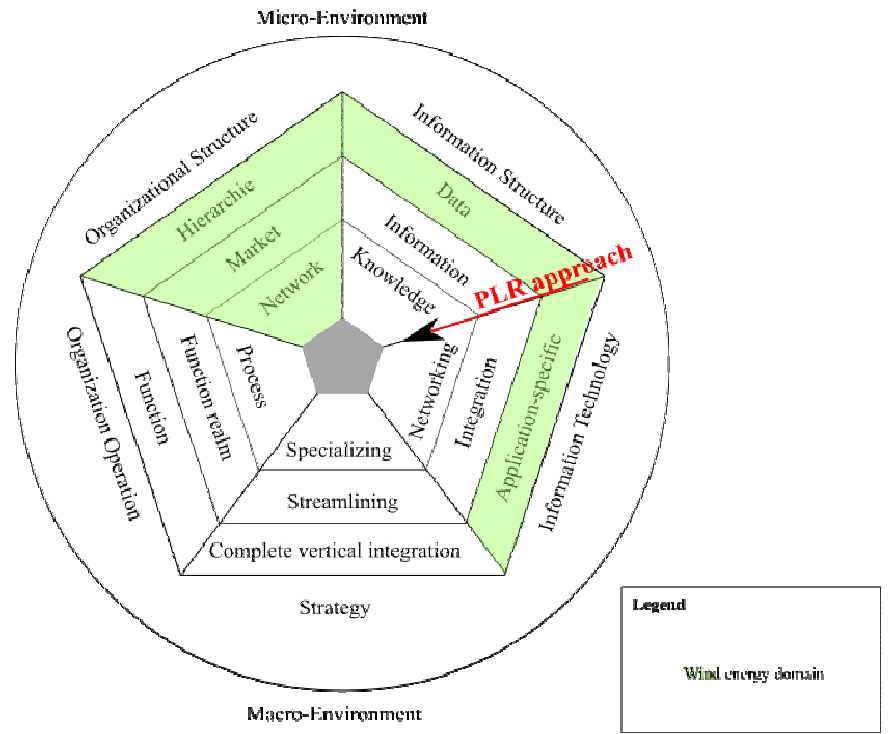

Fig. 1 Business Transformation Pyramid following Ewig [2]

Within the complete lifecycle of a WPP, numerous stakeholders cooperate, especially in the operation phase. Hence, the organizational structure can be classified as a network. Although, most of the business tasks and services are knowledge intensive, the quality of the available information is often insufficient and the data exchange is only semi structured. Thus, the type of information structure is on the level of data. One reason for this situation is the low maturity of information technology. Individual proprietary software products are prevalent, due to low company ages or sizes. No common information system integration approach is established.

To reach more efficient business collaboration in the wind energy domain, the maturity of the information structure and information technology should be increased. The PLR approach explicitly addresses these two dimensions.

For a better understanding of the connection between technology and knowledge, a short excurse to organizational theory is introduced below. 


\subsection{Network Organization, Knowledge and Technology ${ }^{2}$}

Scott describes a direct dependence of technical and structural complexity: "The structural response to technical diversity is organizational differentiation." [9]. A high degree of organizational differentiation also means a high degree of network complexity, which results in a substantial amount of required information in specialized business network activities [10, 11]. Hence, information technology and information distribution mechanisms become increasingly important with a growing complexity of the network. These information distribution mechanisms are the basis for knowledge creation and transfer via information interlinking [12,13]. An efficient knowledge transfer as well as skill transfer across single organizational units become important issues to reduce overall operating costs $[12,14]$. This leads to the perspective on knowledge as a factor of production [15]. Accordingly, organizations integrate individual knowledge into goods and services [16] and "[t]he primary task of management is [to] establishing the coordination necessary for this knowledge integration" [16]. This perspective on organizations and networks is called knowledge-based or -centered ${ }^{3}$. Knowledge integration into services, products, or business activities is characterised by the availability of information as well as personal skills and internalised knowledge. Therefore, it is important to distribute most specific information to the stakeholders using network-oriented information technology, because "the more formal the information system, the fewer the resources consumed in transmission" [10]. The PLR provides such an approach for the distribution and management of plant-related information and supports efficient knowledge transfer between relevant stakeholders.

\section{The Plant Lifecycle Record Approach}

Stakeholders can have different objectives in a value-added network. As a result of a qualitative survey, four ideal-types can be distinguished which refer to their specific needs as well as their expectations on a knowledge-based approach. The structure of the PLR considers these expectations and is introduced shortly in the following. Finally, the application of the PLR is shown by a use case.

\subsection{Stakeholder Expectations and Requirements}

To explore requirements and potentials of a knowledge-centered approach in the wind energy domain, experts have been questioned with the help of an explorative semistructured survey. The qualitative analysis (cross-case and case immanent analysis) of

${ }^{2}$ The presented theoretical background is very similar to virtual organization approaches (e.g. [5-8], which will not discussed here.

${ }^{3}$ This definition of knowledge-centered approaches is similar to [17] and other researcher in the domain of Knowledge Management, which define it "as any approach which can be applied in KM and facilitates the knowledge activities in KM." [17] 
the interviews results in four preliminary types of stakeholder viewpoints (called ideal-types ${ }^{4}$ ):

1. Stakeholders with an information-oriented point of view are mainly interested in structural properties of information. Unification, completeness, comprehensibility and centralisation of information have been mentioned as most important functions for a knowledge-based approach. This leads in the innovation potentials of improved information flows and higher efficiency in general. It can be assumed, that this ideal-type only has insufficient access to required information and seeks for improvements in information organization. Maybe this is the reason why this ideal-type is -in context of a knowledge-centered approach- not interested in dimensions like legal evidence, processes, or business.

2. Stakeholders with a documentation-oriented point of view focus on documentations, particularly on information exchange, historisation, and completeness. A documented history enables transparency and leads to the identified innovation potentials of an improved information flow and higher traceability. The special importance of the documentations suggests that this idealtype mainly works with (technical) documents and does not depend on specific contents that might not be available in general.

3. Stakeholders with a process-oriented point of view concentrate on business processes, activities, and activity data. They refer to information distribution and (legal) evidence instead of information exchange. Furthermore, these stakeholders are interested in activity-tracing. They act as a networking hub of process-based information. From their point of view, the innovation potentials of a knowledgebased approach are the better availability and reusability of process information as well as the improved (legal) safety.

4. Stakeholders with a systemic point of view follow a holistic and systematic understanding of business processes and their structure. Especially, the comparability and effectiveness of information logistics are important concepts for these stakeholders. Probably, they are not actively involved in business process operations, but rather perform managerial functions.

\subsection{Concepts of the PLR}

According to Ewig [2], common information concepts as well as better information system integration are needed to reach a high level of business collaboration maturity. The technical specification DIN SPEC 91303 [19] introduces a generic structure of a Plant Lifecycle Record for sustainable energy resources based on international technical standards. A PLR is defined as a collection of information sets, which consist of an amount of documents, data or both of them. These information sets refer to the following concepts: (1) the plant structure, (2) the product structure, (3) one or more views, (4) the lifecycle phase, and (5) the responsible stakeholders.

${ }^{4}$ An ideal-type is a stakeholder with empirically extracted and exaggerated properties. The ideal-types are disjoint in their interpretations. 
The most important concept of the PLR is the plant structure definition. All information must refer to that structure. In the wind energy domain, the so called Reference Designation System for Power Plants (RDS-PP ${ }^{\circledR}$ ) is relevant [18]. It defines a standardized language to describe the e.g. functional components of the WPP system. Furthermore, it defines a syntax to designate relations between information and the plant structure. The actual product structure of the WPP is managed separately. This enables an overview of every installed product that realized a specific function for the complete lifecycle of the WPP.

A special characteristic of the PLR is the view concept. Based on a classification of the stakeholder information needs, five basic views have been defined. They refer to scopes of responsibilities like commercial, technical, or legal aspects. Every information can be annotated using a set of view meta-data. Accordingly, the stakeholders can access and filter the PLR based on their responsibility with respect to their activity based information needs.

The DIN SPEC 91303 only defines the top level concepts of the PLR. No detailed meta-data is defined. To qualify these concepts, existing and standardized meta-data definitions and information models are applied. This ensures a high degree of interoperability, comprehensibility, and acceptance. The designation and semantics of services for the operation of sustainable energy resources can be found in DIN SPEC 91310 [20]. For WPPs, the ZEUS approach by FGW renewable energies [21] defines the semantics of the plant state. Based on this classification, the actual health and possible resulting tasks can be described in a generally understandable notation. Furthermore, existing complex information models have been taken into account, like the Common Information Model by the IEC [22], or the ISO 15926 and IEC 61400-25 standards [23].

The digital PLR concretises and implements the given concepts of the DIN SPEC 91303. It provides a scalable and highly integrated knowledge base that can be accessed by every member of the value-added network. The digital PLR is an integrated information system that can be used by every stakeholder to manage plantrelated information. A common information model ensures consistent data and information linking.

\subsection{Use Case}

The owner is responsible for the secure operation of a WPP. In the operation lifecycle phase, a so-called operator often undertakes the operation tasks in the name of the owner. In this case, the owner's point of view is systemic, whereas the operator is a process-oriented stakeholder. Based on the PLR, the owner can supervise the operator and compare the information of different WPPs. The operator can use the digital PLR to coordinate the information distribution as well as to analyse the quality and completeness of the available information.

In the context of maintenance and repair, the operator has to coordinate the pending processes of the service providers in charge. The PLR represents a common knowledge base for every partner involved. The service providers take an information-oriented perspective on the PLR. They can directly access the required information and file new documents. The information sets can be exchanged directly 
between the partners. No information conversion or restructuring is needed. The operator only has to check the quality of the new information and can add new links to other relevant information in the PLR. This shared management leads to better information quality, higher actuality of the information and reduced workloads for all involved stakeholders.

The digital PLR approach provides the basis for a structured information exchange between the stakeholders. The improved availability of information reduces the efforts for service preparation and completion. The digital PLR ensures an improved system integration and supports the automation of data exchanges. In total, the business collaboration is strengthen by an improved information technology support.

\section{Conclusion}

Value-added networks for WPPs are complex and highly dynamic. Today, business collaboration between the stakeholders is amendable because of inefficient or broken information flows, which are results of immature information technologies and an insufficient inter-company knowledge management. The digital Plant Lifecycle Record approach addresses these challenges by providing a shared knowledge base whose concepts are premised on international technical standards and information models.

To identify the main innovation potentials and the requirements of the PLR, experts have been questioned. The resulting four preliminary ideal-types are introduced. These types can help to create a theoretical framework to describe the stakeholder-network and interactions for WPPs and beyond. Furthermore, the main concepts of the PLR are derived from the requirements of the ideal-types.

A demonstration implementation of the digital PLR is under development and will be evaluated in different practical use cases. In contrast to DIN SPEC 91303, this prototype will consider requirements like security or system availability in more detail and will provide some decision support methodology.

\section{Acknowledgments.}

This work is a result of the CVtec project, supported by the Federal Ministry of Education and Research (BMBF) as grant 01IS14016C.

\section{References}

1. Fraunhofer Institute for Wind Energy and Energy System Technology (IWES): Wind Energy Report Germany 2013, Kassel. http://publica.fraunhofer.de/dokumente/N287408.html (2014)

2. Ewig, M.: Der Transformationsprozess zum collaborative business. Eine strategische, organisatorische und informatorische Betrachtung. Schriften zur Wirtschaftsinformatik, Bd. 17. Lang, Frankfurt am Main, New York (2006) [German] 
3. March, S.T., Smith, G.F.: Design and natural science research on information technology. Decision Support Systems 15(4), 251-266 (1995). doi: 10.1016/0167-9236(94)00041-2

4. Peffers, K., Tuunanen, T., Rothenberger, M.A., Chatterjee, S.: A Design Science Research Methodology for Information Systems Research. J. of Management Information Systems 24(3), 45-77 (2008)

5. Chai, H., Liu, L., Luo, S.: Knowledge transferring in virtual organization. In: 2011 2nd International Conference on Artificial Intelligence, Management Science and Electronic Commerce (AIMSEC), Deng Feng, China, pp. 3089-3092. doi: 10.1109/AIMSEC.2011.6010369

6. Katzy, B.R.: Design and Implementation of Virtual Organizations Kohala Coast, Hawaii, USA, January 6-9, 1998, p. 142

7. Ahuja, M., Carley, K.M.: Network Structure in Virtual Organizations. J. ComputerMediated Communication 3(4), 0 (1998). doi: 10.1111/j.1083-6101.1998.tb00079.x

8. DeSanctis, G., Monge, P.: Introduction to the Special Issue: Communication Processes for Virtual Organizations. Organization Science 10(6), 693-703 (1999). doi: 10.1287/orsc.10.6.693

9. Scott, W.R., Davis, G.F.: Organizations and organizing. Rational, natural, and open system perspectives, 1st edn. Pearson Prentice Hall, Upper Saddle River, N.J. (2007)

10.Galbraith, J.R.: Organization design: An information processing view. Organizational Effectiveness Center and School 21 (1977)

11.Gulløv, T.: Structural Limitations in Organizational Design. In: Burton, R., Håkonsson, D., Eriksen, B., Snow, C. (eds.) Organization Design, vol. 6. Information and Organization Design Series, pp. 67-83. Springer US (2006)

12.Tsai, W.: Knowledge transfer in intraorganizational networks: Effects of network position and absorptive capacity on business unit innovation and performance. Academy of Management Journal 44(5), 996-1004 (2001). doi: 10.2307/3069443

13.Walter, S.: Logistik in Dienstleistungsunternehmen. Deutscher Universitätsverlag, Wiesbaden (2003) [German]

14.Hill, Charles W. L., Hitt, M.A., Hoskisson, R.E.: Cooperative Versus Competitive Structures in Related and Unrelated Diversified Firms. Organization Science 3(4), 501-521 (1992). doi: 10.1287/orsc.3.4.501

15.Sydow, J., van Well, B.: Wissensintensiv durch Netzwerkorganisation Strukturationstheoretische Analyse eines wissensintensiven Netzwerkes. In: Sydow, J. (ed.) Management von Netzwerkorganisationen, pp. 143-186. Gabler Verlag (2010) [German]

16.Grant, R.M.: Toward a knowledge-based theory of the firm. Strat. Mgmt. J. 17(S2), 109122 (1996). doi: 10.1002/smj.4250171110

17.Ding, W., Liang, P., Tang, A., van Vliet, H.: Knowledge-based approaches in software documentation: A systematic literature review. Information and Software Technology 56(6), 545-567 (2014). doi: 10.1016/j.infsof.2014.01.008

18.VGB PowerTec: RDS-PP - Application Guideline; Part 32: Wind Power Plants (VGB-S823-32-2014-03-EN-DE-0), (2014)

19.DIN: Components and structure of a plant documentation system for renewable energy plants, Berlin (DIN SPEC 91303) (2015) [German]

20.DIN: Classification of services for the technical management of renewable energy plants (DIN SPEC 91310) (2014) [German]

21.FGW: Betrieb und Instandhaltung von Kraftwerken für Erneuerbare Energien - Teil 7 Rubrik D2: Zustands-Ereignis-Ursachen-Schlüssel für Erzeugungseinheiten (ZEUS) (FGW TR 7 D2) (2013) [German]

22.Uslar, M., Specht, M., Rohjans, S., Trefke, J., Vasquez Gonzalez, J.M.: The Common Information Model CIM. IEC 61968/61970 and 62325 - A practical introduction to the CIM, Power Systems, vol. 66. Springer Berlin Heidelberg, Berlin, Heidelberg (2012)

23.IEC: Wind turbine generator systems - ALL PARTS (IEC 61400-SER ed1.0) (2011) 